\title{
Analysis of the Thirsty Planet
}

\author{
Zhuo Zhang \\ School of the North China Electric Power University, Baoding 071000, China. \\ zz605243615@qq.com
}

\begin{abstract}
Will the world run out of clean water? According to the United Nations, one quarter of the world's population experience water scarcity. We construct three models to solve the world's water problems. We establish models for the ability of a region to provide clean water. We apply the SD model to solve the problem. The model is dynamic and it contains the concept of feedback, including a feedback loop and the feedback system. We consider four subsystems, including water resources subsystem, social subsystem, economic subsystem and ecological environment subsystem. For an unknown quantity column in the four subsystems, we write equations, and then make water resources carrying capacity system structure of SD general layout. We give an analysis of the cause's tree. Determine appraisal index water resources carrying rate I. When $\mathrm{I}>1$, that is beyond the carrying capacity of water resources. When $0<\mathrm{I}<1$, it is in the water resources carrying capacity of critical state. The model test is divided into two parts, dimensional consistency and check consistency.
\end{abstract}

Keywords: SD model; water resources carrying rate; model test.

\section{Introduction}

Will the world run out of clean water? We see this water scarcity problem becoming exacerbated with climate change and population increase. According to the United Nations, 1.6 billion people (one quarter of the world's population) experience water scarcity. Therefore, it is very urgent to solve the problem of water pollution. There are two primary causes for water scarcity: physical scarcity and economic scarcity. Physical scarcity is where there is inadequate water in a region to meet demand. Economic scarcity is where water exists but poor management and lack of infrastructure limits the availability of clean water. We should consider several factors to solve the problem of water pollution.

We develop a model that provides a measure of the ability of a region to provide clean water to meet the needs of its population. We need to consider the dynamic nature of the factors that affect both supply and demand in your modeling process.

\section{Models for the Ability of a Region to Provide Clean Water}

\subsection{The Principle of the Model.}

We apply the SD model to solve the problem. The essence of SD model[1] is: analyze causality and feedback loop within systems and between systems; select state variables and the speeds and auxiliary variables; establish a system flow chart, and then establish a feedback loop between variables in the system; use finite difference method on the timeline analog variable changes with the time development; analyze the trend of the development of the system, and adjust the key variable affecting the development of the system in order to reflect the effects of that policy. Basic steps are as follows

a. System analysis .The main task of system analysis is to analyze problems, analyze the system. Investigate system relevant information and data, analyze the system of basic problems and the main problems, the main variables and a preliminary system defined boundaries.

b. The analysis of system structure. The main task is to deal with system information and analyze system of feedback mechanism; divide the level of the classification system and sub-block; analyze the relationship between variables; determine the loop and feedback loop between the relationships.

c. Establish a standard mathematical model. SD model mainly includes the flow chart and the structural equation. Design the flow chart on the basis of the relationship of various factors; structural 
equation is the embodiment of the quantitative relationship between the factors. System flow chart is the core part of the whole system structure, making the mechanism of action of the system internal more clearly.

d. Model simulation .Use Vensim ${ }^{[2]}$ simulation software for simulation.

e. The result analysis and system model of correction. In order to see if the simulated test reaches the expected goal, or to test if the system structure is flawed, we should analyze the simulation results; According to the results of simulation analysis, modify the system model. The flow chart is as follows.

\subsection{The Bearing Capacity of Water Resources System Dynamics Model.}

From the system dynamics point of view, there are at least two problems: a. it is dynamic; $b$. it contains the concept of feedback, including a feedback loop and the feedback system.

The analysis of water resources-ecological-social and economic system

Water resources subsystem analysis

According to different sources of water resources, regional water resources is mainly composed of surface water resources and groundwater resources, also include other regional water resources, such as sewage reuse water, water desalination and rainfall.

Social subsystem analysis

Social subsystem water requirement refers to domestic water, including two parts of the urban life and rural life in the use of water. The main factors are population, distribution and migration.

Economic subsystem analysis

According to industry classification law, all economic activities can be divided into primary industry, secondary industry and tertiary industry. The first industry is the agriculture. We mainly consider irrigation farming, forest land and pasture irrigation. The second industry mainly considers industrial water and industrial water reuse rate. Due to the fact that the water consumption is mainly related to the employees of the tertiary industry, we will take it into the social subsystem to calculate.

Ecological environment subsystem analysis

Ecological environment subsystem mainly consider urban landscaping water requirement, such as city purification system and vegetation system such as grass, vegetation protection forest and artificial landscape irrigation water, etc.

Flow graph model structure

According to the water resources-ecological-social and economic system of the system analysis, system dynamics model of the water resources carrying capacity system can be divided into four subsystems: water resources subsystem, social subsystem, economic subsystem and environment subsystem. Structure diagram is shown in Fig. 1.

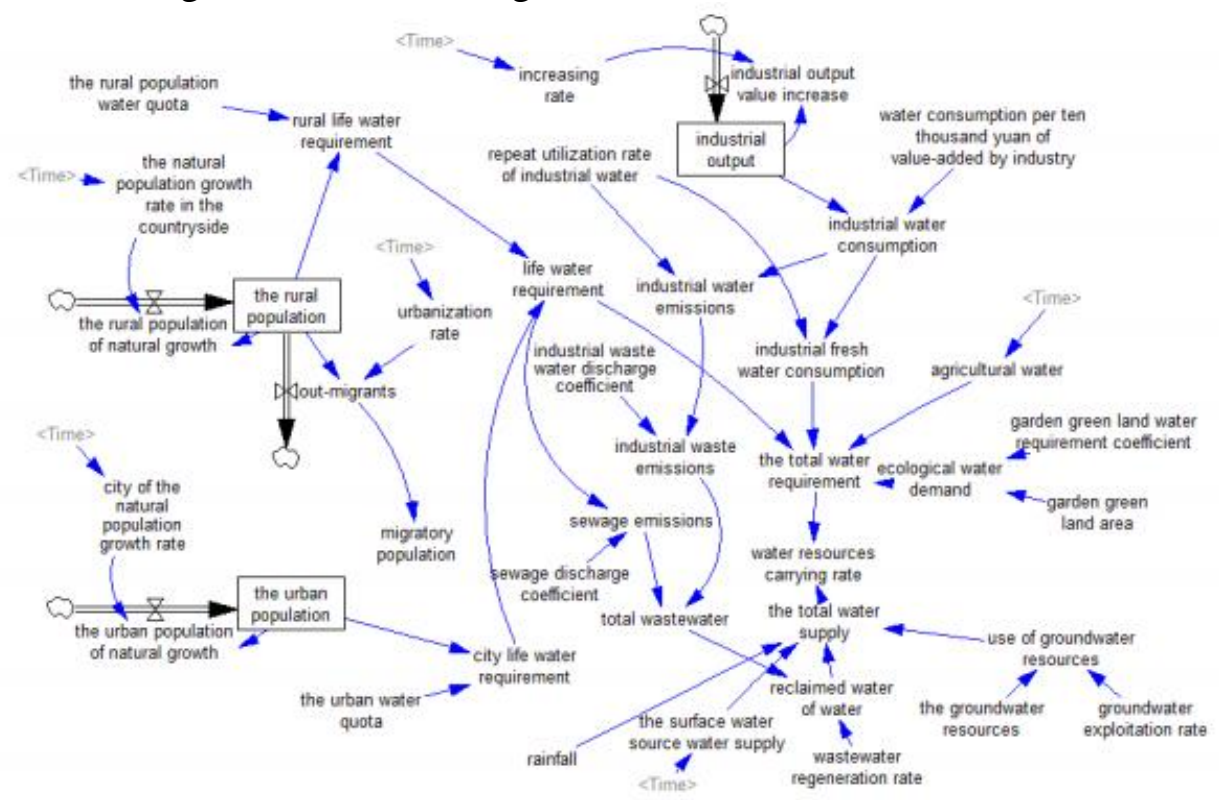

Fig. 1 Structure diagram 
The writing of the main equation debugging

Structural equation refers to the flow and flow rate of the feedback loop. Draw the corresponding system flow diagram. Further we use equation to determine the number of mutual response relationship. The main equation is as follows:

(1) Water resources subsystem analysis

rural life water requirement $=$ the rural population water quota $\times$ the rural population

city life water requirement $=$ the urban population $\times$ the urban water quota

life water requirement $=$ rural life water requirement + city life water requirement

industrial water consumption = water consumption per ten thousand yuan of value-added by industrial $\times$ industrial output

industrial fresh water consumption $=$ industrial water consumption $\times(1$-repeat utilization rate of industrial water)

industrial water emissions $=$ industrial water consumption $\times(1$-repeat utilization rate of industrial water)

industrial waste emissions $=$ industrial waste water discharge $\times$ industrial water emissions

sewage emissions $=$ coefficient sewage discharge coefficient $\times$ life water demand

total waste water $=$ sewage emissions + industrial waste emissions

reclaimed water of water $=$ wastewater regeneration rate $\times$ total waste water

use of groundwater resources $=$ groundwater exploitation rate $\times$ the groundwater resources

(2) Social subsystem analysis

the rural population $=$ INTEG(the rural population of natural growth + the rural populationout-migrants)

the rural population of natural growth $=$ the natural population growth rate in the countryside $\times$ the rural population

out-migrants $=$ urbanization rate $\times$ the rural population

the urban population = INTEG(the urban population of natural growth + the urban population+ migratory population)

the urban population of natural growth $=$ city of the natural population growth rate $\times$ the urban population

migratory population $=$ out-migrants

(3) Economic subsystem analysis

industrial output $=$ INTEG(industrial output value increase + industrial output) industrial output value increase $=$ increasing rate $\times$ industrial output

(4) Ecological environment subsystem analysis

ecological water demand $=$ garden green land water requirement coefficient $\times$ garden green land area

the total water requirement $=$ agricultural water+ life water requirement + industrial fresh water consumption + ecological water demand

the total water supply = reclaimed water of water+ use of groundwater resources + the surface water source water supply + rainfall

water resources carrying rate $\mathrm{I}=$ the total water requirement/ the total water supply

\subsection{Ecological Environment Subsystem Analysis.}

a. Dimensional consistency: Water resources bearing capacity of the system dynamics Model use Vensim simulation software "Check Model" and "Units Check" to do the adaptability test. It includes dimensional consistency; model the boundaries of the suitability of the inspection, etc.

b. Check consistency: Consistency check of the model is mainly to input the historical model simulation parameter, and then compare with the historical data, verify simulation results, thus to determine system consistency. 


\section{Conclusion}

When I > 1, that is beyond the carrying capacity of water resources, and as I value increases, it is more serious overload; When $\mathrm{I}=1$, it is in a critical state of water resources carrying capacity. When $0<\mathrm{I}<1$, it is in the water resources carrying capacity of critical state, and with the decrease of the value I, it can add the greater the carrying capacity.

\section{References}

[1] Li Chuan. Study on the Water Resources Carrying Capacity of Liaoning along Bohai Region for key industries [D]. Northeastern University, 2012.

[2] Information on: http://vensim.com/free-download/.

[3] Information on: http://worldwater.org/. 